\title{
The universal key technologies of Ocean energy power generation
}

\author{
Du Peidong, Zheng Jingjing, Lu Qilong, Wu Yingting ${ }^{2}$ \\ ${ }^{1}$ State Grid Gansu Electric Power Research Institute, Lanzhou, China \\ ${ }^{2}$ State Grid LongNan Electric Power Supply Company, LongNan, China \\ Peidong9@163.com
}

Keywords: Tidal energy; Wave energy; Universal key technology.

\begin{abstract}
With the ocean having become the hot of new energy development, there is a sharp increase in the investment of ocean energy development. Dozens of unites have carried out researches of ocean energy technology under the National Marine Renewable Energy special funds to support. With the depth of the projects, there are many difficulties. Especially there are many universal technical problems in the study of wave and tidal energy. We could not complete the above topics successfully until the key technologies have been grasped. Based on floating anchor and fixed piling equipment for tidal energy and wave energy. In this article, we present the way of ocean energy capture, power transmission (excluding onshore section) and structural optimization. We also describe the design, insulation seal and manufacture of the underwater generator. The universal key technologies will be discussed and analyzed for the reference of the relevant R \& D personnel.
\end{abstract}

\section{Introduction}

With the incoming exhaustion of traditional energy and increasing severity of environmental pollution, many countries increase the development and application of clean energy. Clean energy includes wind energy, solar energy and ocean energy, in which the ocean energy has wide distribution range, large reserves and high energy density, so it is the most important new energy with the development potential in the 21st century. According to the energy application utilization form, ocean energy includes wave energy, tidal energy, tidal current energy, ocean current energy, temperature difference energy and osmotic energy. The tidal current energy and wave energy is more matured and is easier to be implemented from the level of transformation technique, and has the tendency to become the dominant way of developing and utilizing ocean energy. In the process of achieving electric energy from tidal current energy and wave energy, all scientific and technical staffs face motor insulation sealing, shaft dynamic sealing, fixation of equipment and transmission of electric energy. The above universal key techniques can't be mastered completely, so the generation set of ocean energy is still in the stage of prototype design and experiment.

\section{Development Trend of Wave Energy and Tidal Current Energy Power Generation at Home and Abroad}

The development of wave energy power generation started early in China. Guangzhou Energy Institution of Chinese Academy of Sciences finished the first 10w Floating Navigation Mark Power Generation in 1986, and then developed some researches about oscillating water column wave energy power generation. And it burdened the national science and technology support project in 2009, 100kw duck-canard wave energy demonstrating power plant. National ocean technology center finished the first kw-level pendulum power generator in 1995 in our country, and burdened and finished the project, 30kw pendulum wave energy power plant, in 1996. And it was settled in the Great Island in Shandong, which supplies power for the residents on the island. And it burdened the national science and technology support project in 2009, research and demonstration of 100kW pendulum wave energy power plant key technique [2]. 


\section{Fixed Forms of Device}

The generation set can be installed and fixed at the bottom of the sea, and it can be installed at the bottom of the floating body. The fixed forms are divided into floating mooring and seabed pilling, which are applied widely.

Floating mooring. The device is fixed on mooring point by anchor chain, which has advantages of easy construction and little influence by sea level, but has the advantages of bad ability avoiding disaster under extreme environment. And it can't ensure safe and reliable power transmission under the environment of tidal fluctuation and under the action of reciprocating ocean current. In domestic coastal region, especially the south-east coastal region in China, the disasters including typhoon are frequent. The floating power generation system needs to notice the survival under the disaster environment. Floating system can be tracked before disaster generates, but it takes great cost to reset mooring system and butt cable again, and the cost may be greater than power generating benefit.

Pile fixation. Piling form is used to fix the bearing frame at the bottom of the ocean. The offshore construction fund investment is great in early stage, but it has evident advantages for reliability and viability. The solid basis not only ensures the working reliability of power generator under ocean, but also ensures the viability of the device under extreme sea conditions. Piling tidal current system is easy to implement the timely submergence before disasters, so the system is widely applied.

\section{Energy Acquisition Ways}

Wave energy acquisition way. Wave energy power generation is difficult to implement energy conversion for two times, and it generally receives three-level conversion. The first level is the conversion from wave energy to machinery energy of a carrier. The second level is the conversion from the energy acquired from the above level to rotating machinery energy. The third level is the conversion from machinery energy to electric energy [3] (Figure 3). But the energy conversion for more levels will reduce the energy, which reduces the conversion efficiency greatly. The advantage of using hydraulic device is that the generator can stably output electric current under the drive of batteries and hydraulic motor. The problems of using hydraulic conversion device are complicated device and heavy weight, and it is difficult to ensure that it works reliably for long time under the state of seawater immersion.

Tidal current energy acquisition way. The greatest advantage of vertical axis tidal current energy power generation device is that there is no steering. And the floating tidal current power generation set can be settled in the cabin. But the velocity is evidently lower than that of horizontal axis way, so the efficiency is low. And the driving rotation speed is low, so it is difficult to use direct-drive mode. When the speed increasing gear is used, the starting velocity of power generation device increases evidently, which evidently reduces the electric energy production of the generator. The greatest problem of vertical floating anchoring power generation set is that the upright weight of the device is great under floating anchoring state, and it is easy to be broken under extreme sea condition. There was the intention of introducing vertical axis tidal current energy power generation technique of Italy, but there was no achievement, the reason for which is that it is dead calm and has good weather in Mediterranean Sea. And there is no disastrous climate. So the power generation device under the specific environment is difficult to ensure the viability under marine environment. Horizontal tidal current energy device has higher speed, and has evident advantage of efficiency. And it is the mainstream way of ocean tidal current power generation at home and abroad.

\section{Design and Manufacture of Power Generator}

The design, manufacture and insulation sealing of generator is the most important technique of the ocean energy power generation device, and it determines if the power generation system can work under ocean environment. 
Direct-driven generator. The transmission process of direct-driven generator is the directs and easiest. It is the best way to directly immerse it into the sea and use sea water to cool lubrication. Using external-rotor generator can effectively increase tangential velocity of generator rotor, and improve the power generating efficiency. Using fractional-slot winding can evidently reduce the starting speed of power generation device. The generator is immersed in the seawater for long time, so it is the key technique for direct-driven tidal current energy generator to solve the insurability problem of generators. The seabed is shallow in China, and there are fewer seas inputting the generator with the capacity of $100 \mathrm{kw}$. If the unit capacity is greater than $50 \mathrm{kw}$, it may make the size heavier and larger, which increases the difficulty of manufacture, transmission and construction, and increases the cost. The most appropriate way in China is to use direct-driven power generation device with the unit capacity less than $20 \mathrm{kw}$ to compose the array.

Speed-increasing generator. The generators under seawater mostly use planet gear speeder combined with high speed generator. The advantage is to effectively reduce the volume and manufacturing difficulty of generators. Using sealed-cabin tidal current energy power generator firstly needs to overcome the sealing problem of the device under water. With the change of working state and external environment of sealed cabin, the reduction of the temperature in sealed cabin may make external water penetrate. The penetration of less seawater will break metal bearing and speeder gear, which can't be repaired by itself, and the result is that the system is broken. The other difficulty of sealed cabin is that the internal heat is difficult to spread. And the internal temperature of the generator can achieve 300 degree, which not only causes demagnetization of magnetic steel, but also breaks insulation of wires. And the disadvantages of it is that it is difficult to implement low speed start and is difficult to be maintained.

(1) It is difficult to implement low-speed starting. The starting velocity of the power generator with speeder is always from $1.1 \mathrm{~m} / \mathrm{s}$ to $1.4 \mathrm{~m} / \mathrm{s}$, which is close to the highest speed in China. And the speed lasts for short time, which makes that the device can't operate for long time, and can't supply sufficient electricity.

(2) Maintenance is difficult. The gear case and sealed cabin is placed under water, which makes that large parts are more difficult to be changed. And it increases the post-production cost of the device.

\section{Power Transmission System}

All engineering technicians need to solve the problem of power transmission at sea. The transmission can reduce the loss of electricity current by promoting the voltage. The selection of submarine cable is critical, and it should have the advantages of resistance to pressure, insulation sealing and corrosion resistance. For the cable used by us, it is orange polyurethane material and is pressure resistant and anti-corrosion for the external, which can reduce the probability of being bitten by sharks. There is tensile steel wires between cables, which can bear 1 ton of tensile stress.

\section{Conclusions}

The development and utilization of ocean energy not only is potential, but also has realistic significance, and it can provide household electricity for the residents on the island and the energy required by manufacturing fresh water, which not only break the status that the island requires the external energy, but also realizes self-sufficient mode. The electricity energy which can't be consumed by the island can provide energy for the coastal region by grid-connected technology. The ocean energy development is still in exploration state, and there are many technical problems to be solved. How to ensure reliable operation of power generation device under extreme ocean environment is the premise of design and manufacture, and it is the purpose of the design to make the electricity energy transmit to the island continuously. With the operation of demonstrative power plant, the bottleneck restricting the development of ocean power generation is broken, and the core technique is mastered, which lays solid foundation for establishing large-scale ocean energy power station. 


\section{References}

[1] Wang Chuankun, Development of domestic ocean technique [J], Solar Energy, 2009, (1):22-25.

[2] Wang Chuankun, Development of ocean technique in China [J], Solar Energy, 2008, (12):17-20.

[3] You Yage, Li Wei, Liu Weimin, Li Xiaoying, Wu Feng, Development status and prospect of ocean energy power generation technique [J], Power System Automation, 2010,34(14):1-12. 